\title{
Human Immunodeficiency Virus (HIV) Transcripts Identified in HIV-related Psoriasis and Kaposi's Sarcoma Lesions
}

\author{
Stephen E. Mahoney," Madeleine Duvic, *\$ Brian J. Nickoloff," Michael Minshall,"* Louis C. Smith,"\# \\ Christopher E. M. Grifiths,' Stephen W. Paddock," and Dorothy E. Lewis **IIII \\ ${ }^{*}$ Departments of Dermatology and ${ }^{\ddagger}$ Internal Medicine, The University of Texas Medical School, Houston, Texas, 77030; ${ }^{8}$ Section of \\ Dermatology, M. D. Anderson Cancer Center, Houston, Texas 77030; "Departments of Pathology and 'Dermatology, University of \\ Michigan Medical School, Ann Arbor, Michigan 48109; **Departments of Microbiology and Immunology and ${ }^{\# M e d i c i n e, ~ B a y l o r ~}$ \\ College of Medicine, Houston, Texas 77030; Integrated Microscopy Resource, University of Wisconsin, Madison, Wisconsin 53706; \\ and Director, "IIIImmunology Core Center for AIDS Research, Veterans Administration Medical Center, Houston, Texas 77030
}

\begin{abstract}
Persons with HIV infection sometimes develop aggressive psoriasis or Kaposi's sarcoma (KS) not usually seen in other immunosuppressed patients. However, a specific and direct pathophysiological role for HIV-1 in these AIDS-associated disorders remains unclear since HIV has not been easily detected in these skin lesions. By combining in situ hybridization with the sensitive detection technique of confocal laser scanning microscopy, we have demonstrated HIV RNA transcripts in 5 of 15 lesional skin biopsies from HIV-infected psoriasis patients, and in 3 of 8 Kaposi's sarcoma biopsies from HIV-infected patients. HIV transcripts were not detected in normal appearing skin from HIV-infected patients or in psoriatic and normal skin biopsies from uninfected individuals $(P=0.006)$. Although previous attempts to demonstrate viral sequences in psoriasis and KS lesions have been unsuccessful, in situ hybridization with confocal microscopy has shown the presence of HIV RNA transcripts predominantly within $\mathrm{CD4}^{+}$, Factor XIIIa positive dermal dendrocytes. HIV or cytokines produced by infected cells in skin lesions may therefore play a direct role in the pathogenesis of HIV-associated psoriasis and KS. (J. Clin. Invest. 1991. 88:174-185.) Key words: in situ hybridization • confocal microscopy • acquired immunodeficiency syndrome • dermal dendrocytes
\end{abstract}

\section{Introduction}

Patients infected with HIV frequently develop cutaneous manifestations including severe psoriasis $(1,2)$, Reiter's syndrome (3), and disseminated Kaposi's sarcoma (KS) ${ }^{1}$ (4). The pathogenesis of these diseases in general is unknown. The possibility of a direct role for HIV in cutaneous diseases is raised by the introduction of HIV proviral or transactivating tat sequences into transgenic mice $(5,6)$. In both transgenic mice strains,

Address correspondence and reprint requests to Dr. Madeleine Duvic, Department of Dermatology and Internal Medicine, University of Texas Medical School, 6341 Fannin, MSB 1.186, Houston, TX 77030. Received for publication 15 May 1990 and in revised form 27 December 1990.

1. Abbreviations used in this paper: KS, Kaposi's sarcoma; LC, Langerhans cells.

\section{J. Clin. Invest.}

(c) The American Society for Clinical Investigation, Inc.

0021-9738/91/07/0174/12 \$2.00

Volume 88, July 1991, 174-185 epidermal hyperproliferation was evident, but in mice with proviral HIV, histologic features of psoriasis (acanthosis and parakeratosis) were also present (6). Male offspring of mice transgenic for tat developed vascular lesions which were similar histologically to Kaposi's sarcoma (5). In human skin biopsies from AIDS/KS patients studied using immunofluorescence and electron microscopy, Langerhans cells (LC) were shown to be infected with HIV (7). However, other investigators have failed to demonstrate in vivo infection by HIV-1 of LCs from normal skin biopsies of HIV seropositive patients using immunohistochemical techniques (8) or using in situ hybridization, the polymerase chain reaction, and transmission electron microscopy (9). Thus, whether LCs are infected in lesional skin of HIV infected patients remains controversial.

Nickoloff et al. recently demonstrated that both $\mathrm{KS}$ and psoriatic lesions contain abundant dermal dendrocytes that are of monocytic origin, distinct from LCs, because they do not express CD1 and are recognized by their expression of Factor XIIIa $(10,11)$. These dermal dendrocytes were suggested to be candidates for HIV-1 infection because of their phagocytic potential as well as expression of $\mathrm{CD}_{4}$, lymphocyte function-associated antigen (LFA-1), and intercellular adhesion molecule (I-CAM-1) (11). Moreover, dermal dendrocytes have been suggested to be the proliferating cell in $\operatorname{KS}(10,11)$ and to be capable of stimulating endothelial, epidermal, and mononuclear cell proliferation via cytokines $(6,10)$. KS cells are known to produce cytokine RNAs for IL-1B and basic fibroblast growth factor (bFGF), which could stimulate endothelial cell and $\mathrm{KS}$ cell proliferation $(12,13)$. However, because genomic sequences of HIV and other viruses have not been detected in $\mathrm{KS}$, an indirect role for HIV has been suggested (14-16).

These observations led to the hypothesis that HIV infection of keratinocytes and/or dermal dendrocytes might be a factor in the pathogenesis of HIV-associated psoriasis and KS. To examine this hypothesis, we used in situ hybridization (17) and confocal laser scanning microscopy (18) to examine skin biopsies from HIV-infected patients and normal controls.

\section{Methods}

Control and test specimens. All patients and controls gave informed consent in accordance with a protocol approved by the Institutional Review Board. HIV infection was confirmed by Western Blotting (Dupont Co., Wilmington, DE) and all patients had routine biopsies clinically diagnostic of psoriasis or Kaposi's sarcoma (Table I). All skin biopsies obtained were immediately fixed in $4 \%$ paraformaldehyde for 3-4 $\mathrm{h}$ and then embedded in paraffin.

Slide preparation (19). To prevent loss of tissue during hybridization, microscope slides were cleaned overnight in $10 \%$ extran (Thomas 
Table I. Skin Biopsies from 21 Male HIV-infected Patients with Either HIV-associated Psoriasis, HIV-associated Kaposi's Sarcoma, or Both

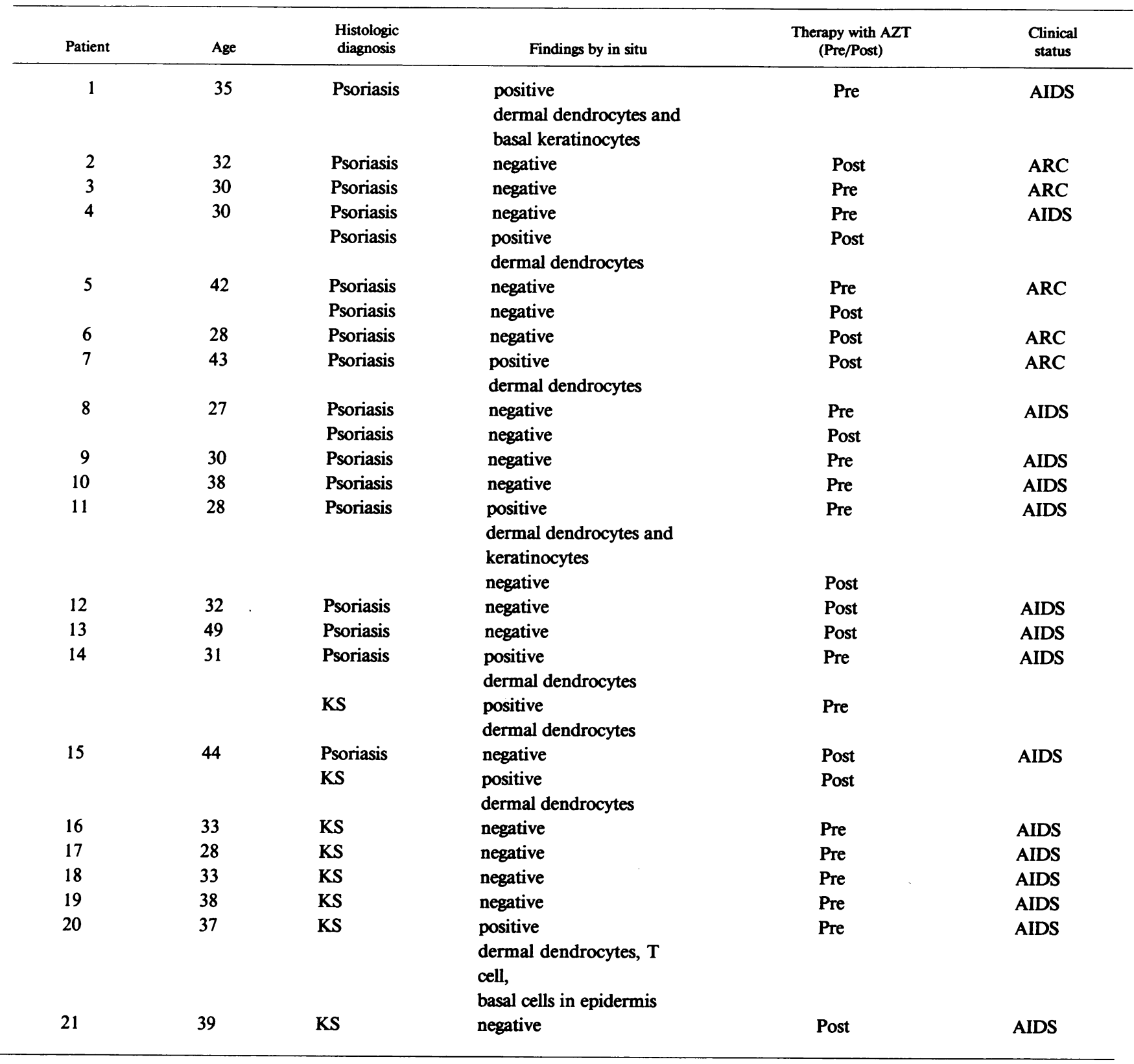

All skin biopsies were coded and analyzed in blinded fashion by in situ hybridization (17) and laser scanning confocal microscopy (18) (Mahoney, S.E., M. Minshall, D. Lewis, and S.W. Paddock). ARC, AIDS related complex.

Scientific, Swedesboro, NJ) and washed in $60^{\circ} \mathrm{C}$ running tap water for $2 \mathrm{~h}$. Slides were then dried at $160^{\circ} \mathrm{C}$ in an oven and cooled to room temperature. They were then immersed in freshly prepared $2 \%$ 3-aminopropyltriethyoxysilane (Sigma Chemical Co., St. Louis, MO) in dry acetone for $1 \mathrm{~h}$. After the washes in dry acetone and in distilled water, slides were placed in poly-L-lysine (Sigma Chemical Co.) $100 \mu \mathrm{g} / \mathrm{ml}$ for $1 \mathrm{~h}$ then allowed to dry overnight at $42^{\circ} \mathrm{C}$. Slides can then be stored at room temperature for several weeks until needed.

Riboprobe preparation. In situ hybridization was performed with a ${ }^{35}$ S-labeled HIV antisense riboprobe (1-2 kb long, SST I-SST I viral insert containing $3^{\prime}$ LTR, $3^{\prime}$ orf, and part of the envelope genes from HIV clone lambda B4-10 [20] subcloned into the pGEM vector pSP64) (Oncor Laboratories, Gaithersburg, MD). The ${ }^{35}$-labeled antisense RNA was transcribed (from the Sp6 promoter region) to a specific activity of $1.0 \times 10^{7} \mathrm{cpm} / \mu \mathrm{l}$. A second HIV probe pSP73-gag-pol con- taining a 1,240 bp Bal1-Pst 1 fragment from HIV isolate $\mathrm{Hx} 82$ was used to generate antisense (Sp6) ${ }^{35}$ S-labeled probes that hybridize to full length unspliced HIV message. The opposite T7 transcript was used as a negative control HIV, sense probe. An antisense riboprobe, which hybridizes to K14 keratin (1,090-bp insert subcloned into pSP65 vector kindly provided by Elaine Fuchs, University of Chicago) (21), was used as a positive control probe for the presence of mRNA on all skin biopsies, while a probe to the bacterial plasmid pGEM with no insert was used as a negative control probe for background hybridization in skin (Stratagene, La Jolla, CA). The ${ }^{35} \mathrm{~S}$-labeled riboprobes were transcribed from T7 (pGEM) and Sp6 (keratin) promoter regions to a specific activity of $1.57 \times 10^{6} \mathrm{cpm} / \mu \mathrm{l}$ (pGEM) and $1.43 \times 10^{6} \mathrm{cpm} / \mu \mathrm{l}$ (keratin).

In situ hybridization (17). Four micron thick sections of $4 \%$ paraformaldehyde fixed paraffin embedded skin biopsies were placed on poly-L-lysine-treated slides. After xylene treatment and rehydration 

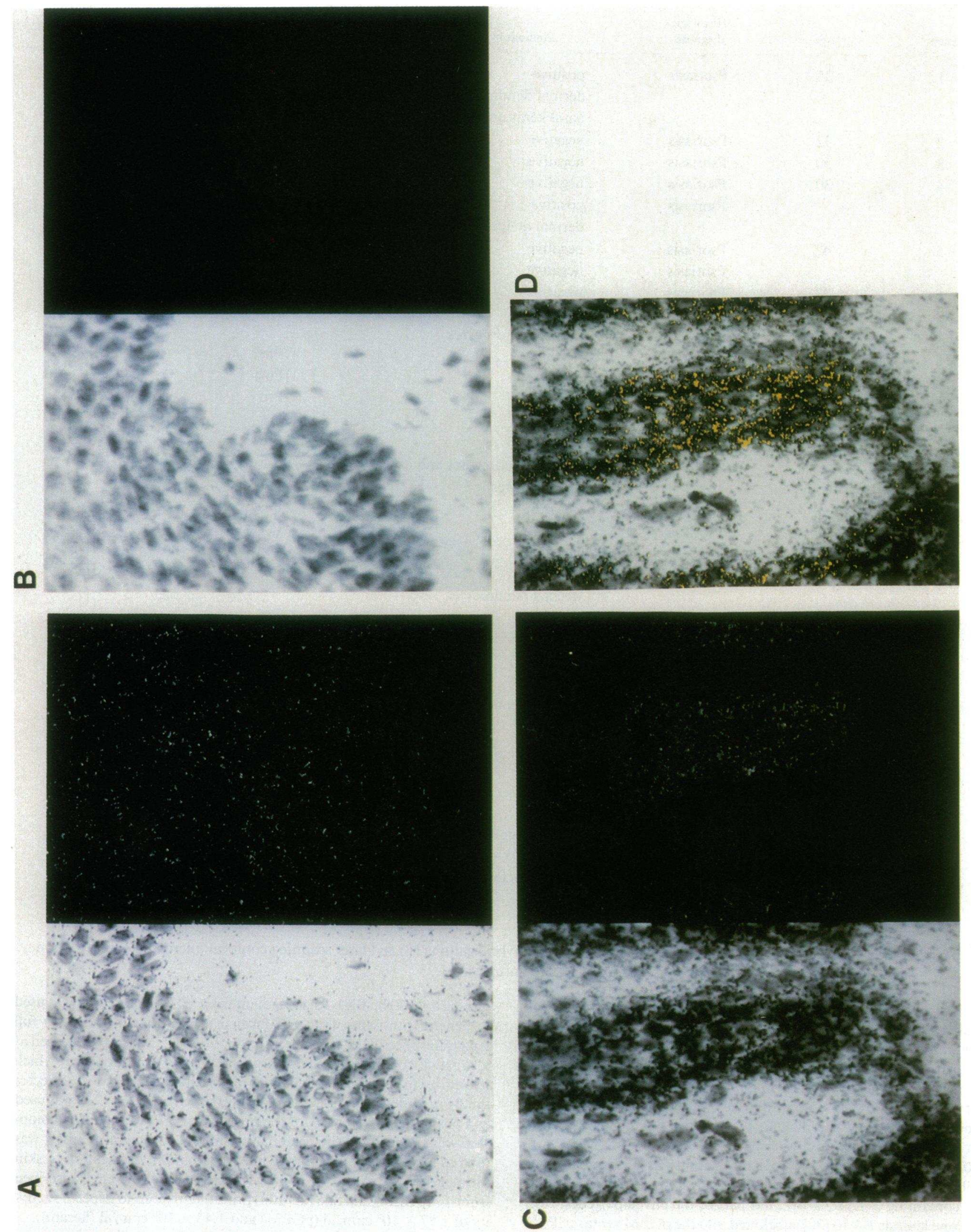

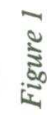




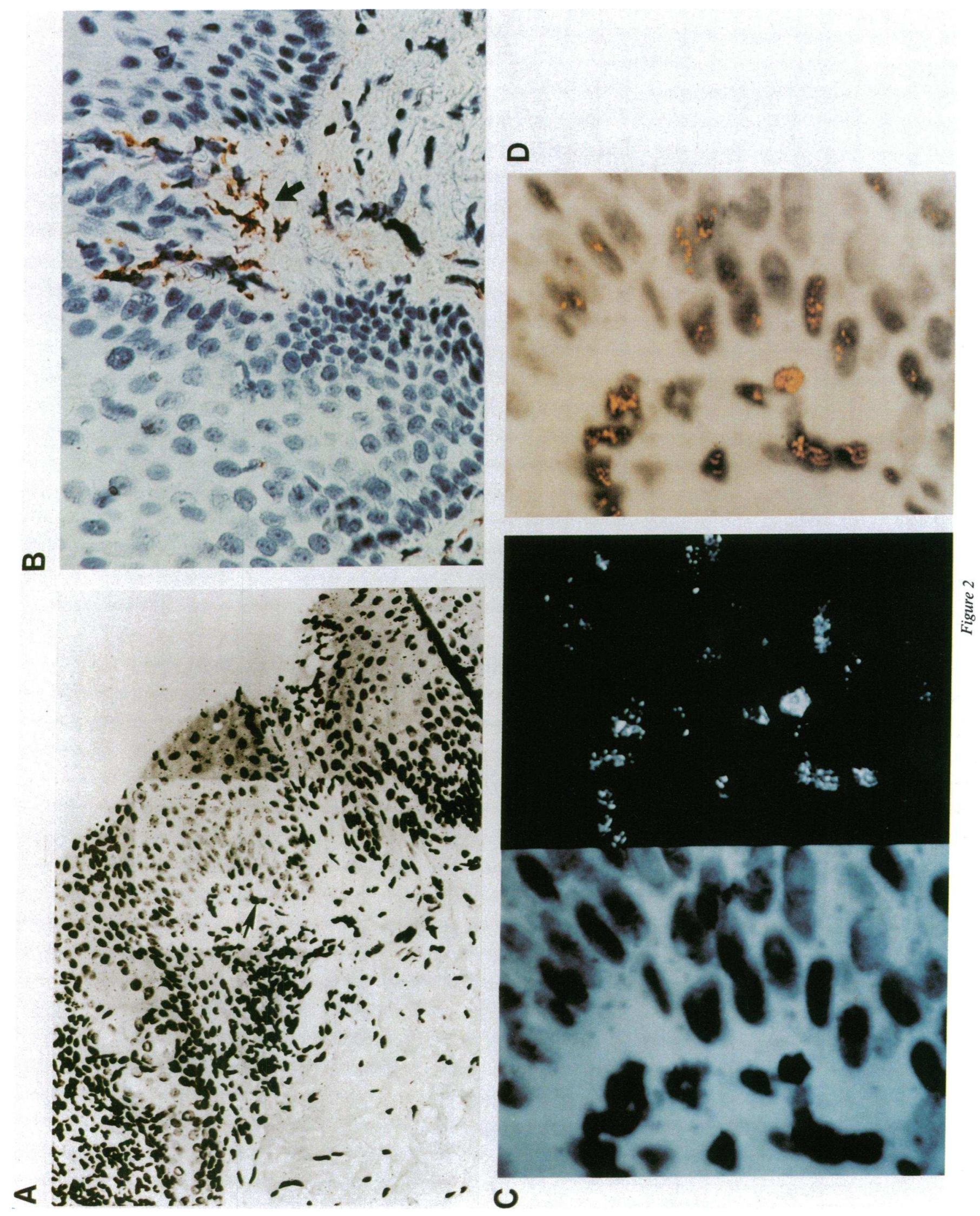



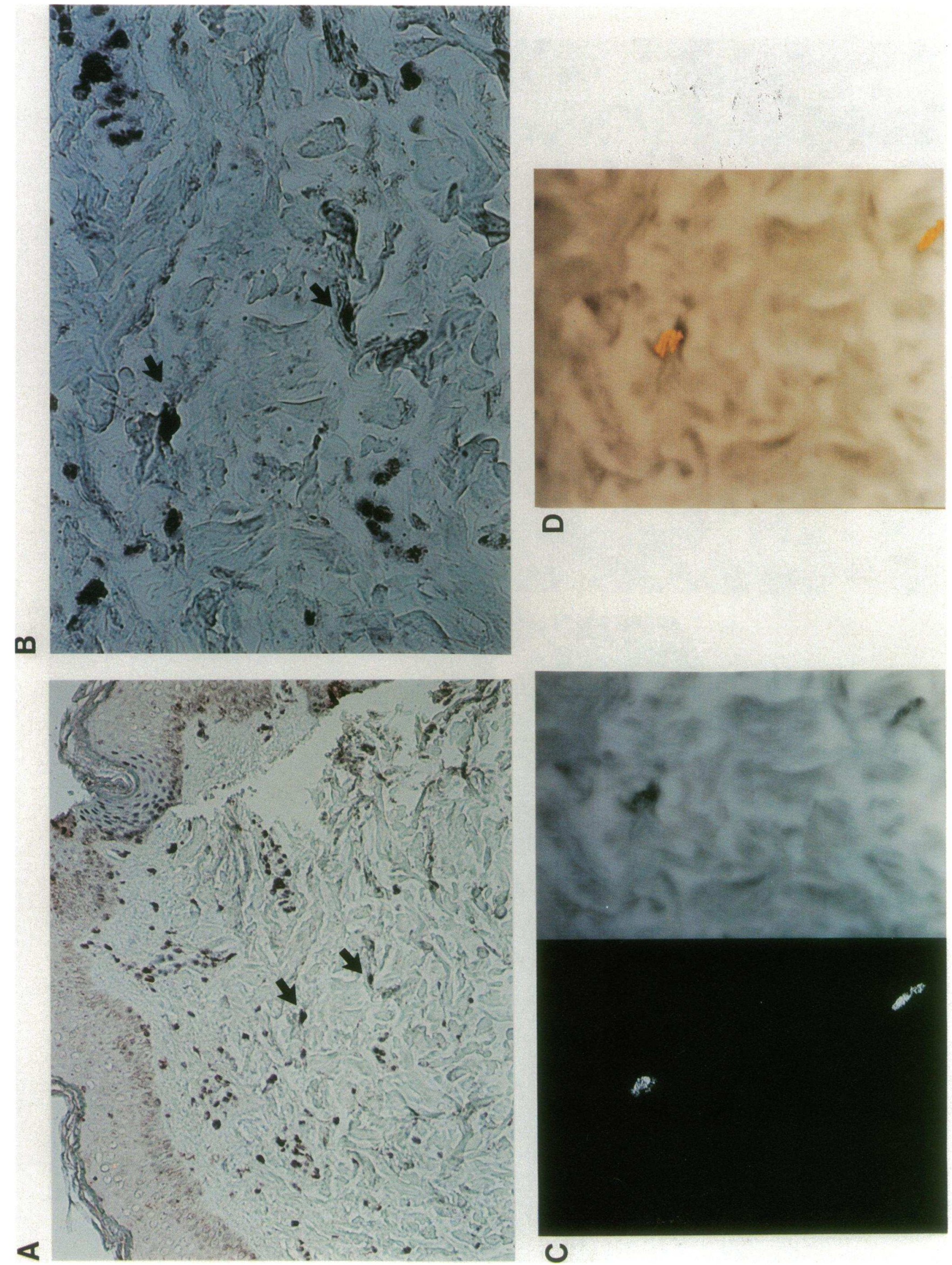
Table II. Summary of In Situ Hybridization Results to HIV Probe

\begin{tabular}{lcc}
\hline \multicolumn{1}{c}{ Patient groups } & Total patients & Positive by in situ \\
\hline HIV-associated psoriasis & 15 & 5 \\
Non-HIV-infected psoriasis & 6 & 0 \\
HIV-associated KS & 8 & 3 \\
Non-HIV-infected KS & 1 & 0 \\
HIV-infected normal skin & 5 & 0 \\
Non-HIV-infected skin & 17 & 0 \\
\hline
\end{tabular}

through alcohol series, slide preparations were acetylated with $0.1 \mathrm{M}$ triethanolamine ( $\mathrm{pH} 8.0$ ) and $0.25 \%$ acetic anhydride $\times 10 \mathrm{~min}$. Slides were then treated with $0.1 \mathrm{M}$ tris $\mathrm{HCL}(\mathrm{pH} \mathrm{7.0)}$ and $0.1 \mathrm{M}$ glycine $\times 30$ min followed by proteinase $\mathrm{K}$ (Sigma Chemical Co.) $1 \mu \mathrm{g} / \mathrm{ml}$ at $37^{\circ} \mathrm{C}$ $\times 30 \mathrm{~min}$. To ensure that hybridization of $\mathrm{HIV}$ probe was to viral RNA, not DNA, sections were not subjected to denaturing to prevent DNA strand separation. Hybridization was performed in $50 \%$ formamide, $2 \times \mathrm{SSC}$, and $100 \mathrm{mM}$ DTT for $3 \mathrm{~h}$ at $52^{\circ} \mathrm{C}$. Slides were then incubated in $50 \%$ formamide $/ 2 \times \mathrm{SSC}$ at $52^{\circ} \mathrm{C} \times 20 \mathrm{~min}$, treated with ribonuclease A and T1 (Sigma Chemical Co.) for $30 \mathrm{~min}$, and dehydrated in ethanol. Slides were autoradiographed with Eastman Kodak NTB2 emulsion, exposed at $4^{\circ} \mathrm{C}$ for 7-10 d, developed in Dektol developer, and stained with geimsa or hemotoxylin and eosin stain.

Immunoperoxidase staining (11). In order to colocalize HIV transcripts within cells, immunoperoxidase staining was performed after the hybridization washes and before emulsion was applied. Antibodies were selected based on their ability to be used on paraffin embedded fixed tissue. A polyclonal rabbit antibody to Factor XIIIa (Calbiochem Corp., La Jolla, CA) 1:400 dilution and antibodies to S-100 (staining melanocytes and Langerhans cells) and to UCHL-1 (T cells) were purchased from Dako, Santa Barbara, CA and used at 1:250 dilution. After in situ hybridization, serial sections were rehydrated and incubated with phosphate buffered saline at $37^{\circ} \mathrm{C}$ for $30 \mathrm{~min}$. Endogenous peroxidase was blocked with $1 \% \mathrm{H}_{2} \mathrm{O}_{2}$ in methanol for $20 \mathrm{~min}$. An avidin-biotin peroxidase technique (Vecta-stain ABC kit; Vector Laboratories, Burlingame, CA) was used for antibody detection with 3-amino 9-ethyl carbazole as the chromagen. After autoradiography, sections were counterstained with $1 \%$ hematoxylin.

Laser scanning confocal microscope analysis. The microscope slides were read at the Integrated Microscopy Resource in Madison, Wisconsin on a Bio-Rad MRC-500 Laser Scanning Confocal Microscope (LSCM) (Bio-Rad Labs., Richmond, CA), which uses a 25-mW argon ion laser as a light source. Specimens were initially reviewed with the conventional light microscope to locate areas of suspected hybrid- ization to the HIV riboprobe. Using the LSCM operated in the reflected light mode, areas of suspected hybridization were confirmed or ruled out. Optical sections were taken at $0.5-\mu \mathrm{m}$ increments through the specimen. Positive hybridization was confirmed if the silver grains remained in the confocal image of the optical sections above the level of nonspecific background. Experiments were repeated three times and were reproducible.

\section{Results}

Table I summarizes the clinical characteristics of the HIV-infected patients with psoriasis and/or KS. HIV-1 RNA transcripts were detected in skin biopsies from 5 of 15 HIV-infected psoriasis patients and in 3 of 8 patients with HIV-associated KS. No hybridization to the HIV riboprobe was noted in 23 HIV negative controls, 5 nonlesional HIV-infected controls, or 1 HIV negative KS patient (Table II). The difference between positive hybridization in all infected $\mathrm{KS}$ and psoriasis lesions $(8$ of 23) versus uninfected controls, with psoriasis, $\mathrm{KS}$, or normal skin (0 of 24), was significant at $P=0.006$ using Fisher's exact test.

No specific hybridization was observed in patients studied using the negative control PGEM riboprobe (Fig. $1, A$ and $B$ ). All patients' skin biopsies demonstrated strong hybridization to basal epidermis using a positive control antisense keratin riboprobe (Fig. 1, $C$ and $D$ ). These two probes were selected to control for the high background in skin specimens, the vector used (pGem), and to confirm the presence of mRNA in biopsies (keratin). Of interest is that Leonard et al. reported that the stratum corneum and hair follicles in skin biopsies from HIV proviral transgenic mice hybridized to an HIV probe (6). Although a similar pattern of hybridization was seen in biopsies with both the HIV riboprobe and the PGEM probe, when viewed with the confocal microscope, this appeared to be nonspecific hybridization in our biopsies.

Positive hybridization in HIV-infected patients with psoriasis (Figs. 2 and 4) was detected in either cells of the dermal papillae or along the dermal/epidermal junction as noted in Table I. Fig. $2 C($ right $)$ reveals numerous silver grains representing HIV-1 viral RNA within cells along the dermal/epidermal junction in an AIDS patient with severe, extensive psoriasis and arthritis (patient 1, Table I). The area indicated by the white square (shown in Fig. $2 A$ ) was bleached by the scanning laser beam. The enhanced confocal image of the enlarged area

Figure 1. Negative and positive control probes. Nonspecific hybridization of HIV negative psoriasis biopsy to pGEM negative control probe. (A) Bright field image (left) taken in the plane of cells, confocal image (right) of the same plane (magnification 200). (B) Bright field image (left) of the plane of the emulsion and corresponding confocal image (right) (magnification 200). Note the absence of silver grains. $C$ and $D$ show positive hybridization with keratin 14 control probe. $(C)$ Bright field image taken in the plane of emulsion $(l e f t)$ (magnification, 200) and confocal image $(r i g h t)$. Note the silver grains localized only to keratinocytes. (D) Colorized overlay of left (bright field) and right (confocal) images of $C$ showing positive hybridization in yellow.

Figure 2. HIV-associated psoriasis. Light microscopy of sections of psoriasis lesion from patient 1 (Table I) showing epidermal acanthosis and dermal inflammatory infiltrates. The lighter square in $A$ (magnification, 100) indicates the area subjected to laser light analysis at the dermal/ epidermal interface. The section shown in $B$ (magnification, 200) has been stained with Factor XIIIa and $1 \%$ hematoxylin (11). On serial sections of same biopsy, numerous dermal dendrocytes staining with Factor XII (arrow) were noted along the dermal epidermal junction $(B)$. $C$ and $D$ (magnification, 400) are from the level of the photographic emulsion so that cells are slightly out of focus in the bright field image. $C(l e f t)$ is the bright field image of lighter square in $A$. $C$ (right) is the confocal image that is shown as a colorized overlay of both images $(D)$. Positive hybridization to HIV probe (yellow grains) is seen in several dermal cells and in cells along the basal layer of the epidermis.

Figure 3. HIV-associated Kaposi's sarcoma. $A$ and $B$ are light microscopy images of a KS lesion (patient 14, Table I). Arrows indicate two dendritic cells within dermis stained $1 \%$ hematoxylin ( $A$ and $B$, magnification, 100 and 200 , respectively). $C$ shows two HIV-1 RNA positive cells that were designated by arrows in $A$ and $B$. Right image is bright field, and left image is confocal image (magnification, 400). (D) Digitally merged image of bright field and confocal images of $C$ showing reflected image of silver grains in yellow. 
A

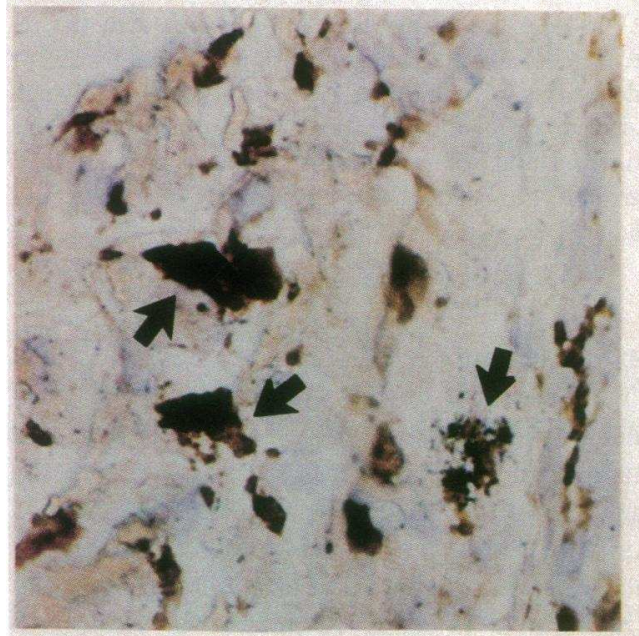

C

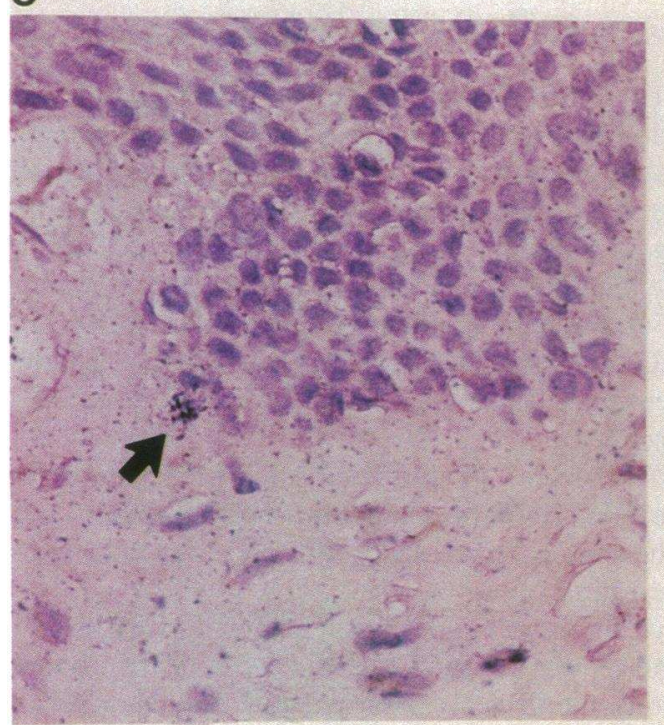

B

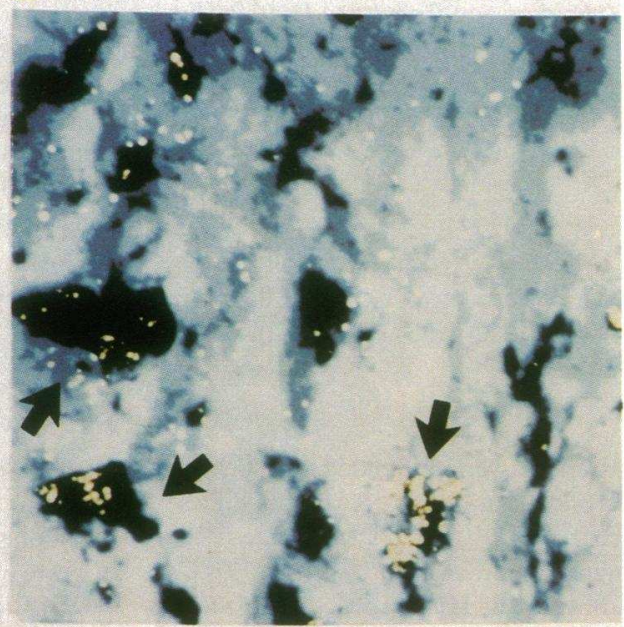

D

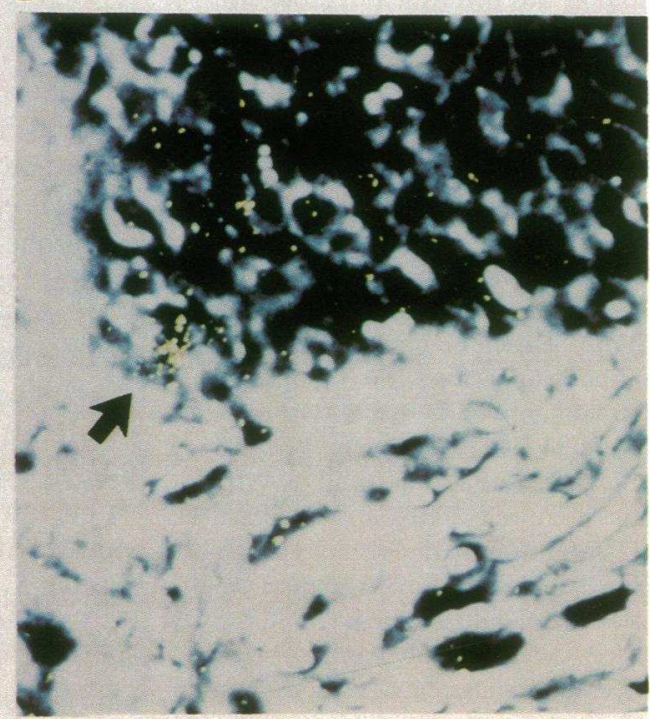

E

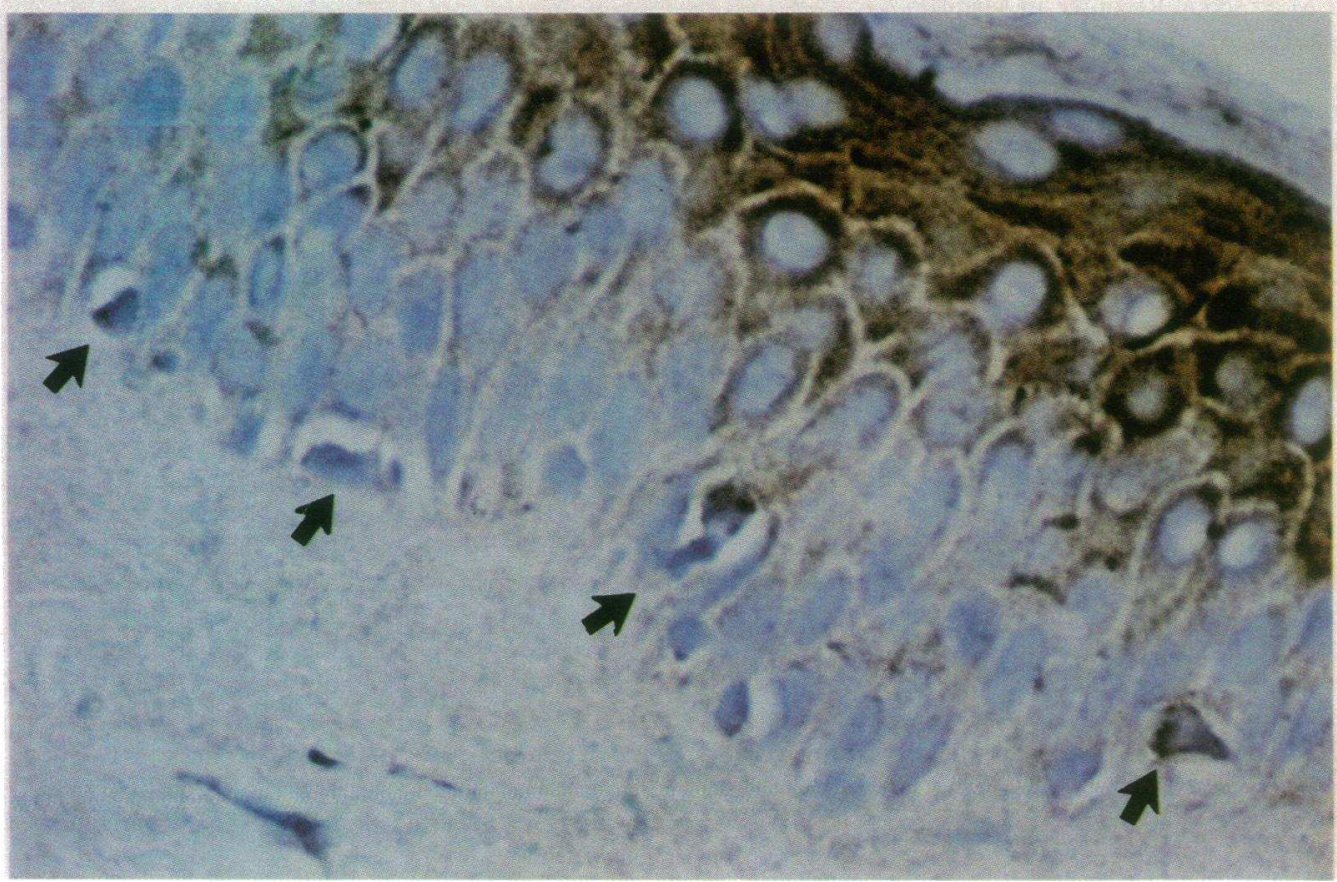

Figure 4. Colocalization of HIV transcripts in psoriasis. $(A$ and $B$ ) Factor XIIIa positive dermal dendrocytes stain brown (see reference 11) (shown by arrows) and also contain HIV RNA transcripts by confocal digital imaging shown as yellow grains (magnification, 400) (biopsy from patient 4, Table 1). ( $C$ and $D$ ) Strong hybridization to cell at base of rete ridge (arrow) (magnification, 100) and to epidermal and dermal cells by confocal imaging $(D)$ Although biopsy was stained with S-100, only the hematoxylin is apparent. $(E)$ S-100 positive epidermal cells

(arrows) (magnification, 400) from case 4 are not positive for HIV transcripts. These cells could be melanocytes or Langerhans cells. 

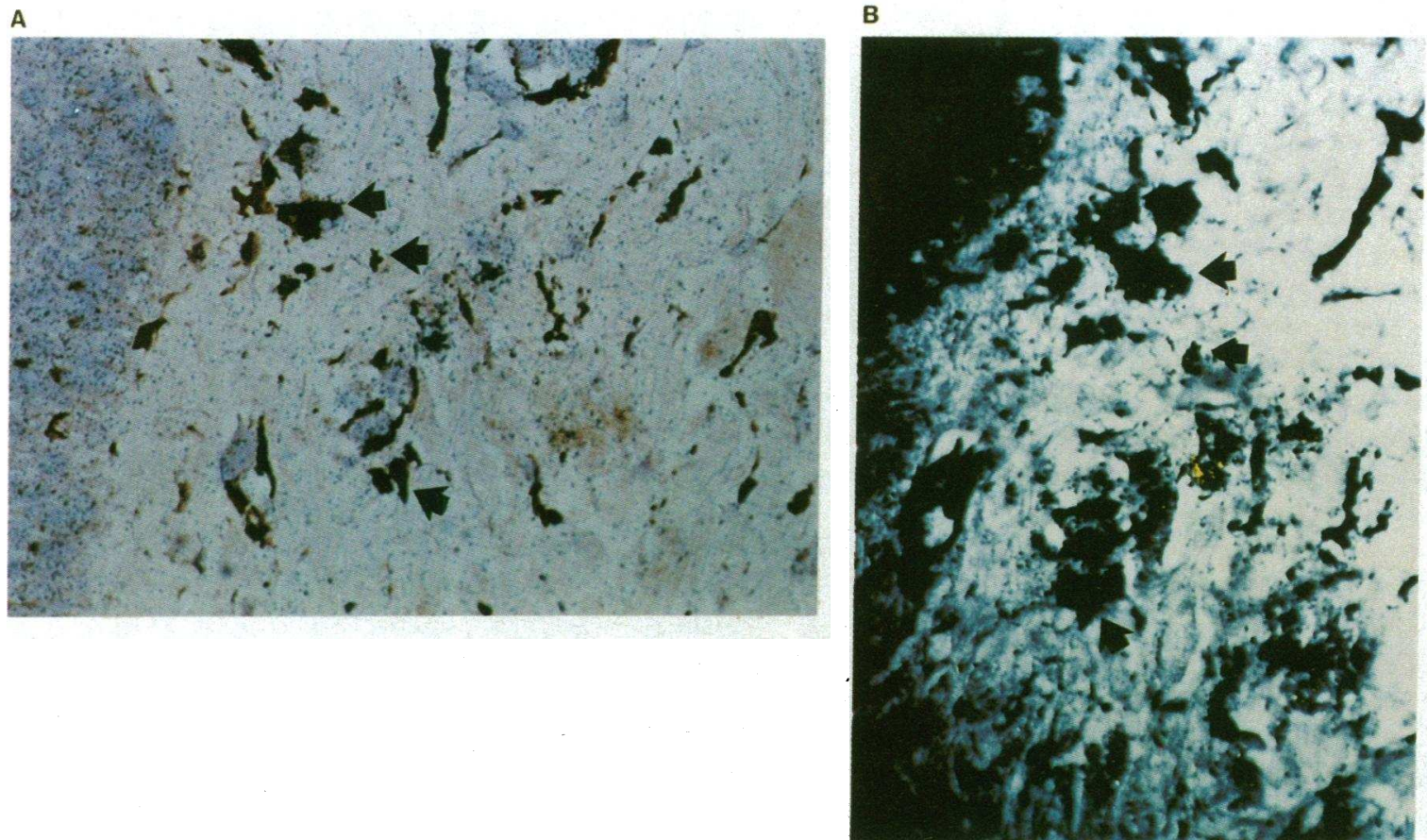

C

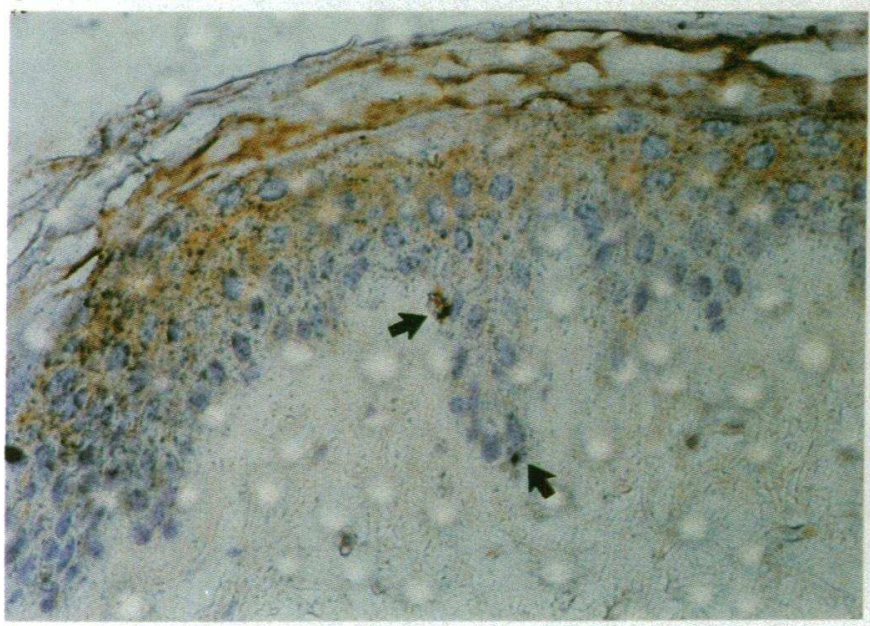

$\mathbf{E}$

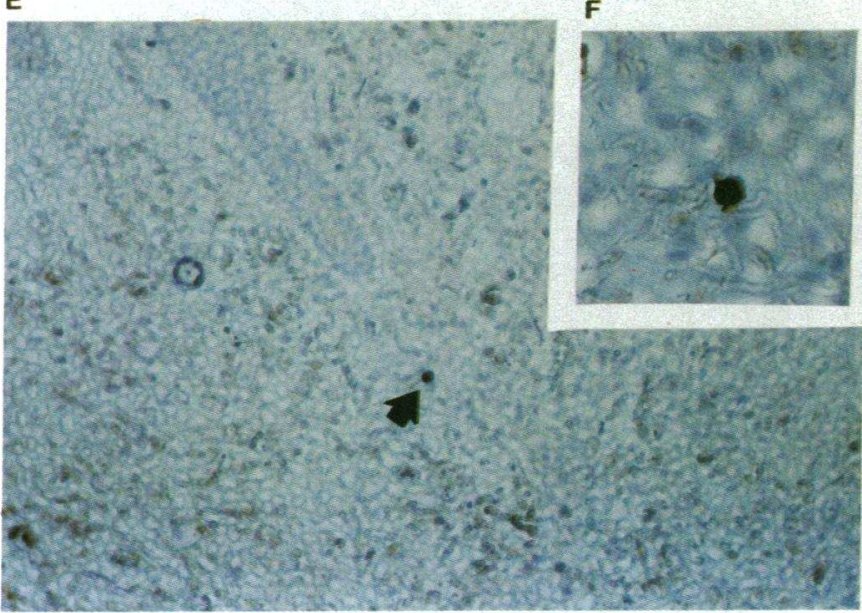

D

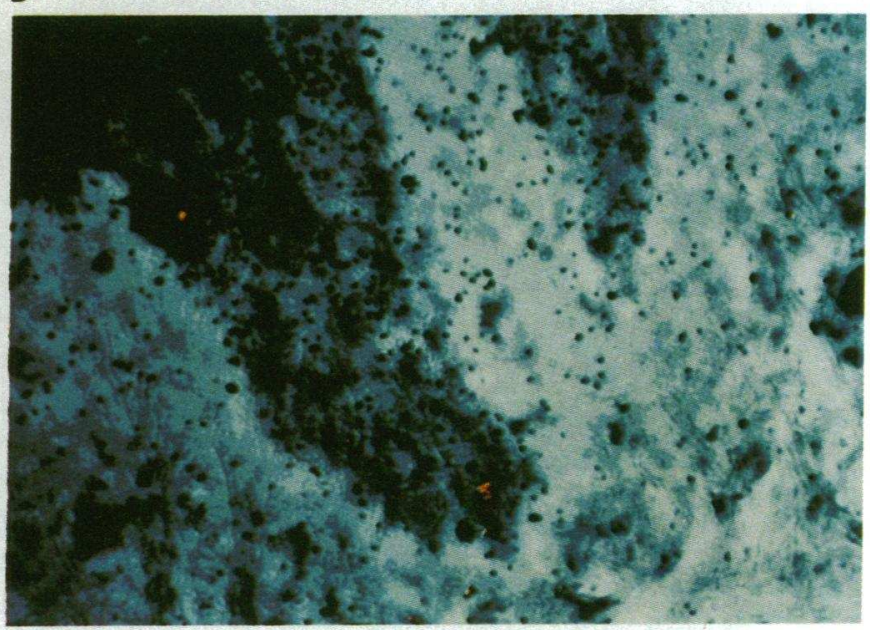

G

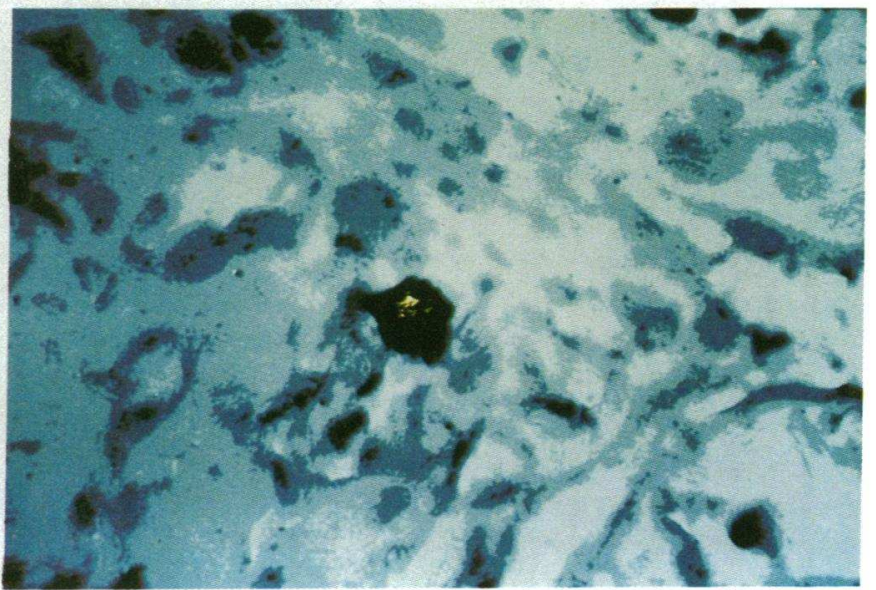

Figure 5 

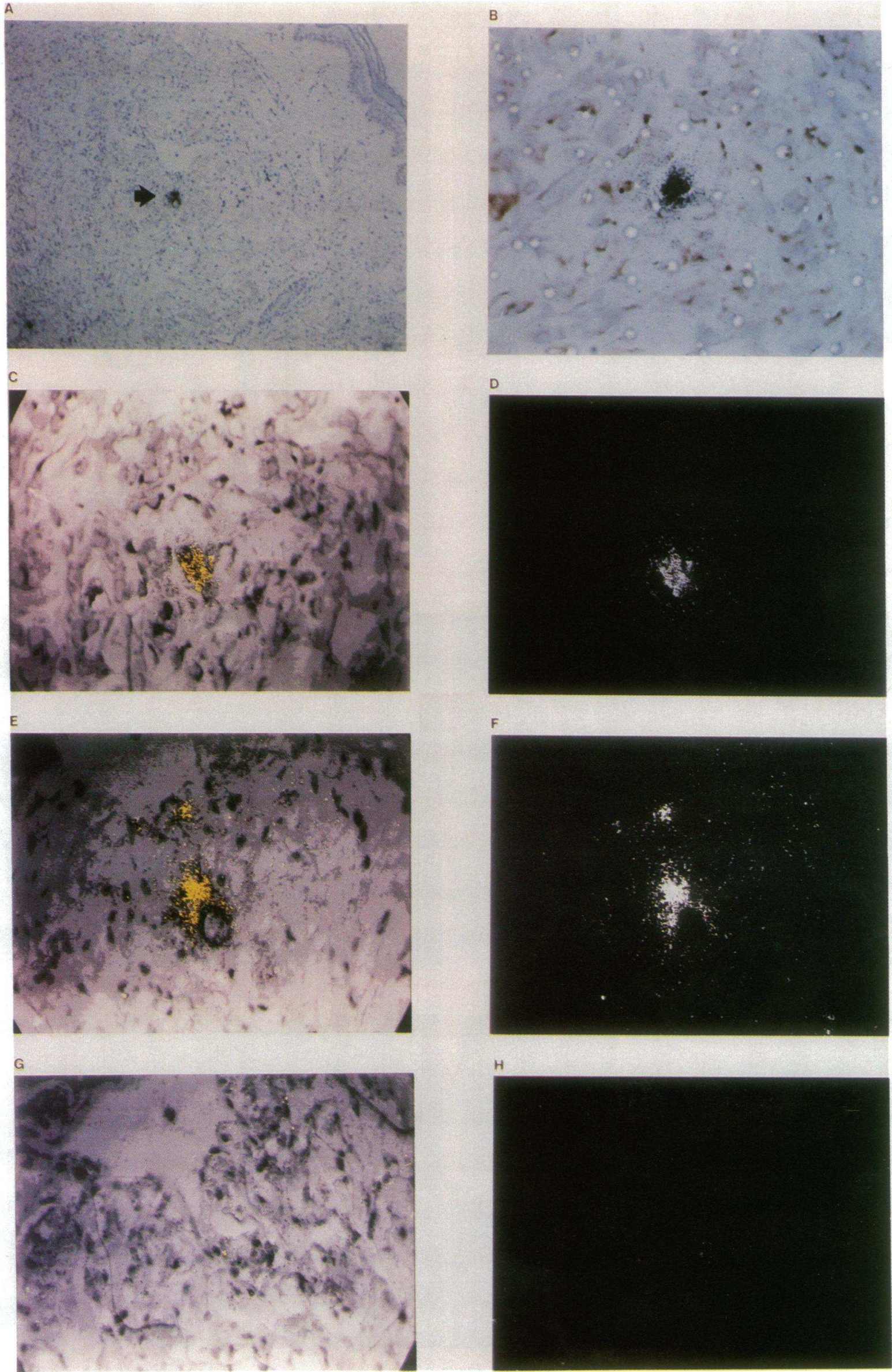
showing positive hybridization within both epidermal and dermal cells is shown in Fig. 2, $C$ and $D$. Three of eight HIV infected patients with KS had HIV viral transcripts detectable within the KS lesions (Figs. 3 and 5). Fig. 3 shows hybridization in two dermal spindle-shaped cells of a KS lesion (patient 12, Table I). This patient also had HIV transcripts within psoriasis lesions.

Paired specimens comparing lesional versus nonlesional skin were examined in four HIV-infected patients (patients 7, 11,19 , and 20 from Table I) and one HIV-infected patient with dysplastic nevi (22). Two of four lesional biopsies (one psoriasis, one KS) revealed HIV transcripts, while all paired nonlesional skin biopsies from HIV-infected patients remained negative by in situ hybridization. Although Duvic et al. previously noted an association with dysplastic nevi in AIDS patients (22), HIV was not present within three dysplastic nevus biopsies studied by in situ hybridization.

Because identification of the cells containing HIV transcripts is of great interest, we next performed colocalization studies on all positive cases available using antibodies that can be used in fixed tissue: Factor XIIIa, S-100, and UCHL-1. Using a highly sensitive immunoperoxidase staining technique for Factor XIIIa, as previously described $(10,11)$, abundant staining of dermal dendrocytes was demonstrated in the upper dermis of all five psoriatic lesions and within the stroma of two KS lesions in areas that were initially positive for HIV transcripts. Fig. $2 B$ shows staining of a psoriatic biopsy with Factor XIIIa revealing many brown staining dendritic cells in the dermal papillae as indicated by the arrow. Fig. $4 A$ and $B$ show colocalization of Factor XIIIa positive dermal dendrocytes with HIV transcripts in a psoriatic lesion. Approximately 10 $20 \%$ of dermal dendrocytes contained transcripts in all biopsies. Two biopsies (Fig. 2, $C$ and $D$ and Fig. 4, $C$ and $D$ ) from patients with AIDS (patients 1 and 11) also had evidence of HIV transcripts within numerous cells of the basal epidermis which appear to be keratinocytes. Fig. $4 C$ (arrow) shows a positive cell at the tip of an epidermal rete ridge whose identity could not be confirmed. However, in all other psoriasis biopsies S-100 positive staining cells in the epidermis (melanocytes or Langerhans cells) were negative for HIV transcripts (Fig. 4 E, arrows).

Two previously positive Kaposi's lesions (from patients 14 and 20) had HIV transcripts within dermal dendritic cells costained with Factor XIIIa (Fig. 5, $A$ and $B$, see arrows, patient 14). However, probe was also localized in three other nondendritic cells as a rare event. Shown in Fig. 5, $C$ and $D$ are two basal epidermal cells, one of which stained with S-100 (left arrow). UCHL-1, which stains T cells, stained several HIV positive cells with the appearance of lymphocytes. One is shown from the dermis of a Kaposi's sarcoma lesion (Fig. 5, $E, F$, and $G)$. As in psoriasis biopsies, the dermal dendrocytes were the main cells containing HIV RNA transcripts, at a frequency of $\sim 10 \%$.

To demonstrate the specificity of the HIV antisense probe, serial sections were hybridized to two different HIV antisense probes and compared with a sense HIV probe (Fig. 6). A strongly positive dermal dendrocyte near a vascular slit (Fig. 6 $A$ ) stained with Factor XIIIa (Fig. 6, B). Using the Oncor HIV antisense probe (Fig. 6, $C$ and $D$, and $E$ and $F$ ), the cell showed HIV transcripts and was similar to the second HIV antisense probe (data not shown). There was no hybridization with the sense HIV negative control probe (Fig. 6, $G$ and $H$ ), as shown by confocal image enhancement and confocal dark field.

\section{Discussion}

We postulate that the use of an HIV riboprobe with high specific activity combined with a sensitive detection system of confocal microscopy explain why we have demonstrated HIV transcripts successfully using in situ hybridization. Difficulties in analyzing in situ hybridization result from contribution of signals from above or below the plane of focus. Silver grains are often positioned at various levels within the emulsion and thus some grains are not visible or appear out of focus by conventional light microscopy (17). Confocal microscopy has been shown theoretically and practically to improve resolution over conventional light or dark field microscopy by providing optical sections of specimens $(18,23)$. The confocal laser scanning microscope, configured to image reflected light, greatly enhances in situ detection by focusing precisely on a shallow plane above the cells within the photoradiographic emulsion where the silver grains accumulate (18). Any part of the sample which is outside a narrow depth of focus is not reimaged at the confocal aperture, thus eliminating most out-of-focus background $(23,24)$.

In Fig. $1 A$, the bright field image (left) is in the plane of focus of the cells and the confocal image (right) reveals the background reflectance caused by the randomly distributed silver grains. In contrast, in Fig. $1 B$, the bright field image is above the plane of focus of the cells (plane of the emulsion) and the corresponding confocal image shows no specific hybridization. Fig. 1, $A$ and $B$ show the nonspecific background caused by random hybridization with the plasmid pGEM probe (negative control). In Fig. $1 C$, the bright field image is within the

Figure 5. Colocalization of HIV transcripts in KS. $A$ and $B$ show Factor XIIla positive dermal dendrocytes, (arrows) (magnification, 200) which coexpress HIV RNA transcripts (yellow grains). $C$ and $D$ show colocalization of HIV transcripts in epidermis overlying KS lesion (patient 20 ). Digital image shows orange grains indicating HIV transcripts $(D)$ are present within two basal epidermal cells (arrows, $C$ ) (magnification, 200). The upper cell on the left is stained brown with S-100, suggesting a Langerhans cell or melanocyte. $E, F$, and $G$ show a single UCHL-1 staining lymphocyte (arrow) within the dermis of a KS lesion (patient 20). E, UCHL-1 (magnification, 40), F (magnification, 200), and digital confocal imaging showing HIV transcripts in yellow (magnification, 400).

Figure 6. HIV RNA transcripts are specific for antisense probe. This figure is representative of the difference in hybridization seen with either of two HIV antisense probes $(A-F)$ compared with sense $(G, H)$ using serial sections through KS lesion (patient 20). $A$ (magnification, 10) shows area of positive hybridization near vascular slit (arrow), which was hybridized with an Oncor HIV envelope probe from B4-10 HIV strain and stained with $1 \%$ hematoxylin. This section is shown as a confocal overlay $(E)$ and darkfield $(F)$ showing positive signal at magnification 400 . The cell shown by the arrow in $A$ is shown in the next section to stain brown with Factor XIIIa $(B)$ and express HIV RNA transcripts by confocal overlay $(C)$ and dark field $(D)$. Note that the halo to the right of the positive cell in $E$ does not appear in the next section $6 \mathrm{C}$ and thus is an artefact. The next section hybridized to the sense negative control HIV probe shows no specific hybridization $(G$ and $H)$ (magnification, 400$)$. 
plane of emulsion, and the confocal image reveals the specific hybridization of the keratin riboprobe to the basal epidermis. An overlay of the bright field image of Fig. $1 C$ and a color enhanced confocal image is shown in Fig. $1 D$.

Although there is evidence for an indirect role for HIV in causing KS and psoriasis via cytokine production (12-15), our results also support the hypothesis that HIV could also have a direct role in their pathogenesis. Recent findings by Ensoli et al. that the tat protein induces KS cell growth, further support a direct role of HIV in the formation of these lesions (25). A direct role may also be suggested by the observation that AIDS patients receiving zidovudine (AZT), which inhibits viral transcription, have a rapid and dramatic clearing of their psoriasis (26). Likewise, zidovudine and $\alpha$-interferon combination therapy also has resulted in improvement or even resolution of KS lesions in HIV-infected patients (27). Shaw et al. have reported HIV in monocytic cells of central nervous system lesions in patients with AIDS dementia using in situ hybridization (28), while others have reported a decrease in HIV transcripts after administration of zidovudine (29). However, we were unable to show a correlation between the use of zidovudine and the presence of HIV transcripts in psoriatic or KS lesions in this small study.

The significance of RNA transcripts in skin cells could have many implications. Skin, especially mucous membranes, might be the site of initial HIV infection with resultant spread to other susceptible populations such as T cells (30) or Langerhans cells. However, we found little evidence for Langerhans cell infection in the lesions studied. It is possible that the reduced numbers of Langerhans cells in HIV patients reported by Belsito (31) may make these cells difficult to find. We cannot say for certain whether the heavily labeled basal cells seen in two psoriasis lesions or in one KS lesion (with positive S-100 staining) were Langerhans cells or melanocytes. Presence of viral transcripts within keratinocytes is suggested in two psoriasis biopsies (patients 1 and 11) with advanced AIDS. Lewis et al. have shown that the number of HIV infected peripheral blood cells increases with stage of disease by similar in situ hybridization studies (32). Keratinocytes could theoretically acquire HIV by nonspecific phagocytosis in spite of the fact that they lack CD4 receptors. Furthermore, since psoriatic epidermal non-LC antigen presenting cells activate $T$ cells (33), infected psoriasis lesions might also trigger HIV replication in skin.

The predominant HIV infected cells in both $\mathrm{KS}$ and psoriasis are dermal dendrocytes of monocytic origin, which express $\mathrm{CD}^{+}$, LFA-1, and Factor XIIIa (11). These cells may act as a reservoir for virus, express cytokines (9-11), and/or produce viral proteins like tat (25), which could lead to proliferative skin disease (12-14). These cells are probably bone marrow derived and may, like Langerhans cells, alternate between skin and lymphoid tissue. Unrelated to HIV infection, both psoriasis and KS lesions share angiogenesis as well as abundant dermal dendrocytes as histopathologic features (11). In psoriasis, epidermal proliferation is pronounced and angiogenesis is an early and mild feature, while in $\mathrm{KS}$, angiogenesis predominates. Because other skin diseases characterized by increased dermal dendrocyte populations including granuloma annulare, cutaneous $\mathrm{T}$ cell lymphoma, and dermatofibromas are characterized by epidermal hyperproliferation, cytokines produced by dermal dendrocytes may drive this hyperplasia (11).

HIV-1 RNA sequences in the skin associated with psoriatic and $\mathrm{KS}$ lesions from HIV-infected patients suggest that a direct role of HIV in the pathology of these lesions cannot be ruled out, or infected dermal dendrocytes may, through cytokine production, indirectly produce these lesions (12-14). Further studies with patients before and after AZT therapy are necessary to see whether clinical improvement is mirrored by decreased production of HIV transcripts in the skin. The development of future antiviral drug strategies must now consider the possible presence of HIV within the skin, as well as in the central nervous system (29), as a continued source of viral transmission and latency.

\section{Acknowledgments}

We thank Elaine Fuchs for the keratin probe, Larry Donehauer for additional HIV probes, Pat Sheffield and Wanda O'Brien for technical assistance, Ronald Rapini for helpful discussions, and Jeanette Quimby for manuscript preparation.

This work was supported by National Institutes of Health grants AR-39915 and AR-36546 (to Dr. Duvic); AI-22549 and the VA Medical Center (to Dr. Lewis); AR-38957, 040065 , and 01823 (to Dr. Nickoloff); and HL-15648, HL-27341, and Welch Q343 (to Dr. Smith). Stephen Mahoney was the recipient of a Dermatology Foundation Fellowship sponsored by Beecham Laboratories. The Integrated Microscopy Resource is supported by an NIH grant RR-570.

\section{References}

1. Johnson, T. M., M. Duvic, and R. P. Rapini. 1985. AIDS exacerbates psoriasis. N. Engl. J. Med. 313:1415.

2. Duvic, M., T. Johnson, R. P. Rapini, T. Freese, and A. Rios. 1987. AIDS associated psoriasis and Reiter's syndrome. Arch. Dermatol. 123:1622-1632.

3. Winchester, R., D. H. Bernstein, H. O. Fischer, R. Enlow, and G. Solomon 1987. Reiter's syndrome and the acquired immunodeficiency syndrome. Ann. Intern. Med. 106:19-26.

4. Friedman-Kien, A. E., L. J. Laubenstein, P. Rubinstein, E. BuimoviciKlein, M. Marmor, R. Stahl, I. Spigland, K. S. Kim, and S. Zolla-Pazner. 1982. Disseminated Kaposi's sarcoma in homosexual men. Ann. Intern. Med. 96:693700.

5. Vogel, J., S. H. Hinrichs, R. K. Reynolds, P. A. Luciw, and G. Jay. 1988. The HIV tat gene induces dermal lesions resembling Kaposi's sarcoma in transgenic mice. Nature (Lond.). 335:606-611.

6. Leonard, J. M., J. W. Abramczuk, D. S. Pezen, R. Rutledge, J. H. Belcher, F. Hakim, G. Shearer, L. Lamperth, W. Travis, T. Fredrickson, A. L. Notkins, and M. A. Martin. 1988. Development of disease and virus recovery in transgenic mice containing HIV proviral DNA. Science (Wash. DC). 242:1665-1670.

7. Tschachler, E., V. Groh, M. Popovic, D. L. Mann, K. Konrad, B. Safai, L. Eron, F. D. Veronese, K. Wolff, and G. Stingl. 1987. Epidermal langerhans cellsA target for HTLV-III/LAV infection. J. Invest. Dermatol. 88:233-237.

8. Kanitakis, J., C. Marchand, H. Su, J. Thivolet, G. Zambruno, D. Schmitt, and L. Gazzolo. 1989. Immunohistochemical study of normal skin of HIV-1-infected patients shows no evidence of infection of epidermal langerhans cells by HIV. AIDS Research and Human Retroviruses. 5:293-301.

9. Kalter, D. C., J. J. Greenhouse, J. M. Orenstein, S. Schnittman, H. E. Gendelman, and M. S. Meltzer. 1990. Langerhans' cells in human immunodeficiency virus infection. Clin. Res. 38:679a. (Abstr.)

10. Nickoloff, B. J., and C. E. M. Griffiths. 1989. Factor XIIIa-expressing dermal dendrocytes in AIDS-associated cutaneous Kaposi's sarcomas. Science (Wash. DC). 243:1736-1737.

11. Nickoloff, B. J., and C. E. M. Griffiths. 1989. The spindle-shaped cells in cutaneous Kaposi's sarcoma: histologic simulators include factor XIIIa dermal dendrocytes. Am. J. Path. 135:793-800.

12. Nakamura, S., S. Z. Salahuddin, P. Biberfeld, B. Ensoli, P. D. Markham, F. Wong-Staal, and R. C. Gallo. 1988. Kaposi's sarcoma cells: long-term culture with growth factor from retrovirus-infected CD4+ T cells. Science (Wash. DC). 242:426-430.

13. Ensoli, B., S. Nakamura, S. Z. Salahuddin, F. Wong-Staal, and R. C. Gallo. 1989. Fifth International Conference on AIDS. WCP48:599a. (Abstr.)

14. Salahuddin, S. Z., S. Nakamura, P. Biberfeld, M. H. Kaplan, P. D. Markham, L. Larsson, and R. C. Gallo. 1988. Angiogenic properties of Kaposi's sarcoma-derived cells after long-term culture in vitro. Science (Wash. DC). 242:430 433.

15. Bovi, P. D., E. Donti, D. M. Knowles III, A. Friedman-Kien, P. A. Luciw, D. Dina, R. Dalla-Favera, and C. Basilico. 1986. Presence of chromosomal abnor- 
malities and lack of AIDS retrovirus DNA sequences in AIDS-associated Kaposi's sarcoma. Cancer Res. 46:6333-6338.

16. Civantos, F., N. S. Penneys, and H. Haines. 1982. Kaposi's sarcoma: absence of cytomegalovirus antigens. J. Invest. Dermatol. 79:79-80, 1982.

17. Harper, M. E., L. M. Marselle, R. C. Gallo, and F. Wong-Staal. 1986 Detection of lymphocytes expressing human T-lymphotropic virus type III in lymph nodes and peripheral blood from infected individuals by in situ hybridization. Proc. Natl. Acad. Sci. USA. 83:772-776.

18. Shotton, D. M. 1989. Confocal scanning optical microscopy and its applications for biological specimens. J. Cell Sci. 94:175-206.

19. Rentrop, M., B. Knapp, H. Winter, and J. Schweizer. 1986. Aminoalkylsilane-treated glass slides as support for in situ hybridization of keratin cDNAs to frozen tissue sections under varying fixation and pretreatment conditions. Histochem. J. 18:271-276.

20. Hahn, B. H., G. M. Shaw, S. K. Arya, M. Popovic, R. C. Gallo, and F. Wong-Staal. 1984. Molecular cloning and characterization of the HTLV-III virus associated with AIDS. Nature (Lond.). 312:166-169.

21. Stoler, A., R. Kopan, M. Duvic, and E. Fuchs. 1988. Use of monospecific antisera and cRNA probes to localize the major changes in keratin expression during normal and abnormal epidermal differentiation. J. Cell Biol. 107:427446.

22. Duvic, M., L. Lowe, R. P. Rapini, S. Rodriguez, and M. Levy. 1989. Eruptive dysplastic nevi associated with human immunodeficiency virus infection. Arch. Dermatol. 125:397-401.

23. White, J. G., W. B. Amos, and M. Fordham. 1987. An evaluation of confocal versus conventional imaging of biological structures by fluorescence light microscopy. J. Cell Biol. 105:41-48.

24. Baak, J. P. A., F. B. J. M. Thunnissen, C. B. M. Oudejans, and N. W. Schipper. 1987. Potential clinical uses of laser scan microscopy. Appl. Opt. 26:3413-3416

25. Ensoli, B., G. Barillari, S. Z. Salahuddin, R. C. Gallo, and F. Wong-Staal.
1990. TAT protein of HIV-1 stimulates growth of cells derived from Kaposi's sarcoma lesions of AIDS patients. Nature (Lond.) 345:84-86.

26. Duvic, M., A. Rios, and G. W. Brewton. 1987. Remission of AIDS-associated psoriasis with zidovudine. Lancet. i:627.

27. Kovacs, J. A., L. Deyton, R. Davey, J. Falloon, K. Zunich, D. Lee, J. A Metcalf, J. W. Bigley, L. A. Sawyer, K. C. Zoon, H. Masure, A. S. Fauci, and H. C. Lane. 1989. Combined zidovudine and interferon-alpha therapy in patients with Kaposi's sarcoma and the acquired immunodeficiency syndrome (AIDS). Ann. Int. Med. 111:280-287.

28. Shaw, G. M., M. E. Harper, B. H. Hahan, L. G. Epstein, D. C. Gajdusek, R. W. Prie, B. A. Navia, C. K. Petito, C. J. O'Hara, J. E. Groopman, E.-S. Cho, J. M. Oleske, F. Wong-Staal, and R. C. Gallo. 1985. HTLV-III infection in brains of children and adults with AIDS encephalopathy. Science (Wash. DC). 227:177182.

29. Yarchoan, R., P. Brouwers, A. R. Spitzer, J. Grafman, B. Safai, C. F. Perno, S. M. Larson, G. Berg, M. A. Fischl, A. Wichman, R. V. Thomas, A Brunetti, P. J. Schmidt, C. E. Myers, and S. Broder. 1987. Response of humanimmunodeficiency-virus-associated neurological disease to 3-azido-3-deoxythymidine. Lancet. i:132-135.

30. Berger, R., S. Gartner, C. A. Foster, M. Popovic, K. Guogenberger, K Wolff, and G. Stingl. 1988. Langerhans cells infected with HIV-1 in vivo and in vitro, can transmit virus to other hematopoietic cells. Clin. Res. 36:632a. (Abstr.)

31. Belsito, D. V., M. R. Sanchez, R. L. Baer, F. Valentine, and G. J. Thorbecke. 1984. Reduced Langerhans cell Ia antigen and ATPase activity in patients with the acquired immunodeficiency syndrome. N. Engl. J. Med. 310:12791282.

32. Lewis, D. E., M. Minshall, N. Wray, S. W. Paddock, L. C. Smith, and M. M. Crane. 1990. Confocal microscopic detection of human immunodeficiency virus RNA-producing cells. J. Infect. Dis. 162:1373-1378.

33. Baadsgaard, O., A. K. Gupta, S. Taylor, C. N. Ellis, J. J. Voorhees, and K. D. Cooper. 1989. Psoriatic epidermal cells demonstrate increased numbers and function of non-Langerhans antigen-presenting cells. J. Invest. Dermatol. 92:190-195 